Basile Henriot, Emmanuel Rouger, Chloé Rousseau, Martine Escoffre, Martine Sébillot, Claude Bendavid, Stéphane Minvielle, Hervé Avet-Loiseau, Olivier Decaux and Caroline Moreau*

\title{
Prognostic value of involved/uninvolved free light chain ratio determined by Freelite and N Latex FLC assays for identification of high-risk smoldering myeloma patients
}

https://doi.org/10.1515/cclm-2018-1369

Received December 24, 2018; accepted March 15, 2019; previously published online April 11, 2019

\section{Abstract}

Background: Smoldering multiple myeloma (SMM) is an asymptomatic plasma cell disorder with a high risk of progression to symptomatic multiple myeloma (MM). The serum free light chain (sFLC) ratio is a powerful prognostic factor for SMM: an SFLC ratio $\geq 8$ has been reported to be associated with a high risk of progression to $\mathrm{MM}$, and an sFLC ratio $\geq 100$ has been described as a criterion for ultrahigh-risk SMM, and has been integrated into the definition criteria for MM since 2014. However, all recommendations were based on sFLC measured using the first commercialized assay, Freelite ${ }^{\mathrm{TM}}$, while other assays are now available. We aimed to evaluate the safety and accuracy of N-Latex sFLC to identify high-risk and ultra-high-risk SMM.

Methods: The sFLC ratio was measured at diagnosis with both Freelite and N-Latex assays in a cohort of 176 SMM patients on a BN Prospec nephelometer. Demographic,

*Corresponding author: Dr. Caroline Moreau, Laboratoire de Biochimie-Toxicologie, Hôpital Pontchaillou CHU Rennes,

2, rue Henri Le Guilloux, 35033 Rennes, France; and Univ Rennes, INSERM, INRA, Institut NuMeCan, CHU Rennes, Rennes, France,

E-mail: caroline.moreau@chu-rennes.fr

Basile Henriot: Service de Médecine Interne, Hôpital Sud CHU Rennes, Rennes, France

Emmanuel Rouger: Laboratoire de Biochimie-Toxicologie, Hôpital Pontchaillou CHU Rennes, Rennes, France

Chloé Rousseau: Pharmacologie Biostatistique, Hôpital Pontchaillou CHU Rennes, Rennes, France

Martine Escoffre and Martine Sébillot: Service d'Hématologie Clinique, Hôpital Pontchaillou CHU Rennes, Rennes, France Claude Bendavid: Laboratoire de Biochimie-Toxicologie, Hôpital Pontchaillou CHU Rennes, Rennes, France; and Univ Rennes, INSERM, INRA, Institut NuMeCan, CHU Rennes, Rennes, France Stéphane Minvielle: CRCINA, INSERM, CNRS, Université de Nantes, Université d'Angers, Nantes, France

Hervé Avet-Loiseau: Unité de Génomique du Myélome, Rangueil CHU Toulouse, Toulouse, France

Olivier Decaux: Service de Médecine Interne, Hôpital Sud CHU Rennes, Rennes, France; and Service d'Hématologie Clinique, Hôpital Pontchaillou CHU Rennes, Rennes, France clinical, therapeutic and laboratory data were collected at the time of diagnosis and at follow-up.

Results: Sixty-two patients (35.2\%) progressed to MM within 2 years. Compared to Freelite ${ }^{\mathrm{TM}}$ sFLC, N Latex sFLC ratios $\geq 8$ and $\geq 100$ provided similar performances for the identification of high-risk and ultra-high risk SMM patients.

Conclusions: Our results evidenced that the N-Latex assay could be used for SMM monitoring, like Freelite. However, an N-Latex sFLC ratio $\geq 70$ appears to provide similar performances to a Freelite sFLC ratio $\geq 100$, with a slightly better positive predictive value. Both assays provided accurate identification of high-risk and ultra-high risk SMM patients. These results should be confirmed in an independent study.

Keywords: free light chains; high-risk; myeloma; smoldering multiple myeloma.

\section{Introduction}

Smoldering multiple myeloma (SMM) was defined in 2003 by the International Myeloma Working Group (IMWG) as an asymptomatic precursor state of multiple myeloma (MM) [1], with a 10\% risk of progression to MM per year during the first 5 years [2-4]. In a recent study, Lakshman et al. estimated the proportion of patients progressing at 2,5 and 10 years to be $28.8 \%, 51.0 \%$ and $71.2 \%$, respectively [5]. Numerous predictors for SMM progression have been identified in the last 10 years, enabling the determination of clinical and biological markers of SMM [2, $6-10]$. Among them, the main predictors are bone marrow plasma cells, involved-to-uninvolved serum free light chain (sFLC) ratio, monoclonal proteins and focal lesions on MRI. In 2008, an involved-to-uninvolved sFLC ratio $\geq 8$ was reported to be associated with a high risk of progression (50\% at 2 years) [2, 3]. In 2013, Larsen et al. in a cohort of 586 patients with SMM reported that 90 patients $(15 \%)$ had an sFLC ratio $\geq 100$ with a risk of progression to MM of $72 \%$ within 2 years, [4]. In 2014, the IMWG revised the definition of MM, including new criteria enabling the 
identification of ultra-high-risk SMM (80\% progression at 2 years) and the introduction of treatment before organ damage occurs. One of these criteria is an SFLC ratio of $\geq 100$ with a light chain concentration $>100 \mathrm{mg} / \mathrm{L}[4,11]$. Recently, Wu et al. in a retrospective cohort of 273 SMM patients confirmed that an sFLC ratio $\geq 100$ was a marker for high risk of progression with a median time to progression of 40 months and a $44 \%$ risk of progression of the disease at 2 years [12]. However, the classification of SMM is still under discussion, and different cut-offs to provide markers at diagnosis for risk stratification in SMM have been proposed [5].

The IMWG recommendations and published studies were based on sFLC measured using the first commercialized assay developed in 2001, the Freelite ${ }^{\mathrm{TM}}$ assay (The Binding Site Group Ltd., UK) [13]. However, today other assays are available, including the $\mathrm{N}$ Latex $^{\mathrm{TM}} \mathrm{SFLC} \kappa$ and $\lambda$ (Siemens Healthcare Diagnostics GmbH, Germany) [14], the Seralite ${ }^{\mathrm{TM}}$ assay [15] and an ELISA assay developed by Sebia [16]. Freelite and N Latex sFLC assays have presented favorable analytical performances and a good correlation in identifying abnormal monoclonal sFLC. However, a significant difference in the absolute FLC levels between $\mathrm{N}$ Latex and Freelite assays has been reported: $\lambda$ FLC was significantly higher using $N$ Latex than using the Freelite assay and the differences between the two assays were most evident at high sFLC concentration ranges for $\kappa$ and $\lambda$ sFLC. This is the reason why the two assays cannot be used interchangeably [17-23]. To date, no study has evaluated $\mathrm{N}$ latex performances in newly defined SMM.

Here, taking into account the IMWG recommendations and definitions, we aimed to evaluate the safety and accuracy of N Latex SFLC in identifying high-risk and ultra-high-risk SMM patients.

\section{Materials and methods}

\section{Patients}

We retrospectively studied a multicenter ( 35 hospitals) French cohort of 176 patients diagnosed with SMM on the basis of the IMWG 2003 criteria between 2008 and 2014 [1]. Ninety-five patients were initially included from the Genomgus Study Protocole Hospitalier de Recherche Clinique PHRC (www.clinicaltrials.gov) and 81 patients from the Nantes hospital. Demographic, clinical, therapeutic and laboratory data were collected at the time of diagnosis and followup. Disease progression from SMM to symptomatic MM was defined according to CRAB criteria. Patients with a follow-up time of under 6 months or with disease progression within the first 3 months after inclusion were excluded (they were considered as patients with multiple myeloma or with a primary progressive disease). All patients included signed the non-opposition form. The study was approved by the Ethics Committee.

\section{Laboratory methods}

Serum samples were collected at the time of diagnosis and stored frozen at $-80^{\circ} \mathrm{C}$, centralized in the Rennes or Nantes University Hospital Biochemistry laboratories (France).

sFLC measurements were performed on frozen serum samples and the same thawed specimen, on a BN Prospec ${ }^{\circledR}$ nephelometer (Siemens) using the Freelite and the N Latex SFLC commercial kits. Both assays were performed according to manufacturers' instructions $[13,14]$.

\section{Statistical analysis}

Descriptive statistics are expressed as medians and interquartile ranges for continuous data, and numbers and percentages for categorical data. Agreement between the Freelite sFLC ratio and the N Latex sFLC ratio was analyzed using a $\kappa$ coefficient. A Spearman's coefficient was used to analyze the correlation between Freelite and N Latex. sFLC concentrations were compared on the Bland-Altman plot for the mean difference and the Bland-Altman plots were constructed with SAS-Software Version 9.1 (SAS Institute, Cary, NC, USA). Threshold values were determined, maximizing sensitivity and specificity using the Youden index. Survival curves were determined using the Kaplan-Meier estimator with a 95\% confidence interval (CI). Groups above and below the threshold were compared using a Cox model, and relative risk (RR) with its 95\% CI is presented. Statistical analyses were performed using SAS-Software Version 9.1.

\section{Results}

\section{Patient characteristics}

Our study included 176 patients with a mean age of 62.8 years \pm 10.1 (median 62.5 [56.4-69.7]); the gender ratio was 1:1. One hundred and eight patients had a $\kappa$ monoclonal component and 68 a $\lambda$ monoclonal component. The overall follow-up time was $73.3 \pm 56.7$ months. Patient characteristics are summarized in Table 1. In our cohort, seven patients had anemia with hemoglobin lower than $10 \mathrm{~g} / \mathrm{L}$ but the anemia was not linked to SMM (chronic kidney disease) in any of these cases, and none of these patients progressed to symptomatic MM in fewer than 6 months.

In the first 2 years after diagnosis, 62 patients (35.2\%) progressed to symptomatic MM (Figure 1A); this population and the events observed are similar to those described in previous cohorts of SMM [7, 24]. 
Table 1: Patient characteristics $(n=176)$.

\begin{tabular}{|c|c|}
\hline & Median [Q1-Q3] or n (\%) \\
\hline Age, years & $62.5[56.4-69.7]$ \\
\hline Follow-up, days & 670.5 [333.5-1440.5] \\
\hline \multicolumn{2}{|c|}{ Evolution from SMM to MM during follow-up } \\
\hline Yes & $62(35.2 \%)$ \\
\hline No & $114(64.8 \%)$ \\
\hline \multicolumn{2}{|l|}{ Monoclonal light chain } \\
\hline$\kappa$ & $108(61.4 \%)$ \\
\hline$\lambda$ & $68(38.6 \%)$ \\
\hline Hemoglobin, $\mathrm{g} / \mathrm{L}$ & $13.0[11.6-13.8]$ \\
\hline Platelets, Giga/L & $235.5[200-286]$ \\
\hline Bone marrow infiltration, \% & $14.3[11-20]$ \\
\hline M-spike, g/L with SPE & $19.2[11.9-28.6]$ \\
\hline \multicolumn{2}{|l|}{ Immunoglobulin, g/L } \\
\hline $\lg \mathrm{G}$ & $19.3[8.1-29.4]$ \\
\hline $\lg A$ & $0.7[0.4-3.0]$ \\
\hline $\lg M$ & $0.4[0.2-0.7]$ \\
\hline Creatinine, $\mu \mathrm{mol} / \mathrm{L}$ & $75[64-86]$ \\
\hline Calcemia, $\mathrm{mmol} / \mathrm{L}$ & $2.4[2.3-2.4]$ \\
\hline$\beta_{2}$-Microglobulinemia, $\mathrm{mg} / \mathrm{L}$ & $2.4[2.0-3.1]$ \\
\hline \multicolumn{2}{|c|}{$\kappa$ free light chain for patients with a $\kappa$ monoclonal component, $\mathrm{mg} / \mathrm{L}$} \\
\hline Freelite assay & $49.7[24.5-132.5]$ \\
\hline N Latex assay & $35.8[17.2-102.5]$ \\
\hline \multicolumn{2}{|c|}{$\lambda$ free light chain for patients with a $\lambda$ monoclonal component, $\mathrm{mg} / \mathrm{L}$} \\
\hline Freelite assay & $72.8[23.5-289.5]$ \\
\hline N Latex assay & $99.9[29.9-212.0]$ \\
\hline \multicolumn{2}{|l|}{ sFLC ratio } \\
\hline Freelite assay & $7.9[2.5-25.3]$ \\
\hline N Latex assay & $5.7[2.0-19.2]$ \\
\hline
\end{tabular}

\section{Correlation between Freelite and $\mathbf{N}$ Latex for sFLC measurement}

There was a high correlation between Freelite $\kappa \mathrm{sFLC}$ and $\mathrm{N}$ Latex $\kappa$ sFLC (Spearman's correlation coefficient $\mathrm{r}=0.95$ ); the correlation was good between Freelite $\lambda$ sFLC and $N$ Latex $\lambda$ sFLC (Spearman's correlation coefficient $r=0.87$ ) (Figure 2). As previously described in published papers [17], in the low range for $\kappa$ and $\lambda$ sFLC, higher values were observed with $\mathrm{N}$ Latex assay compared to the Freelite assay (Figure 2A and B). For high $\kappa$ sFLC values, we observed a systematic bias whereby concentrations obtained with the Freelite method were more elevated than those obtained with the N Latex sFLC assay (Figure 2A). In addition, for $\kappa \mathrm{sFLC}$ as for $\lambda$ sFLC, a gap for values around $1000 \mathrm{mg} / \mathrm{L}$ is observed, which is a technical limitation of the Freelite assay (Figure 2A and B). This point is very important and could lead to a different appreciation of the clinical sFLC ratio. sFLC ratio results measured by Freelite and N Latex FLC were correlated $(r=0.81)$. However, the ratios obtained with the N Latex assay were significantly lower than the
Freelite sFLC ratios, and for certain individual patients, more significant differences were observed (Figure 2C), as also reported in previous method comparison studies $[17,18]$.

To compare the Freelite and N Latex assays for the measurement of $\kappa$ and $\lambda$ sFLC concentrations, we also used Bland-Altman plot for mean difference (see Supplementary data). There was no systematic or proportional bias and the difference between methods increased as the concentration of $\lambda$ or $\kappa$ sFLC increased. For $\kappa$ and $\lambda$ sFLC, we observed 10 outliers for $\kappa$ sFLC and three outliers for $\lambda$ sFLC, i.e. $7 \%$ outliers. These patients presented heterogeneous clinical and biological characteristics and outcomes. For $\kappa \mathrm{sFLC}$, eight patients had monoclonal IgG $\kappa$ and two patients had monoclonal $\kappa$ sFLC. Three patients presented an eGFR below $60 \mathrm{~mL} / \mathrm{min}$. Three patients had an SFLC ratio above 100 with both methods and progressed to MM in the study period. Two patients had an sFLC ratio below 100 with both methods and progressed to MM. Three patients had an SFLC ratio above 100 with the Freelite assay (and below 100 with the N Latex assay) and two of them progressed to MM. Finally, two patients had an sFLC ratio below 100 with both methods and did not progress to MM.

For $\lambda$ sFLC, three outliers were observed: two of them had a monoclonal IgG $\lambda$ and one had a monoclonal IgA $\lambda$. None of these patients had renal impairment. One patient with an SFLC ratio above 100 with both methods did not progress to MM. One patient had an SFLC ratio above 100 with the Freelite assay and below 100 with the $\mathrm{N}$ Latex assay, and progressed to MM. The last patient had an SFLC ratio above 100 with the N Latex assay and below 100 with the Freelite assay and progressed to MM. Therefore, the outliers are not driven by one or other of the assays.

\section{Evaluation of an sFLC ratio of 8}

As previously described by Dispenzieri et al. in 2008 and 2009, we first determined an N Latex sFLC ratio associated with a high risk of progression [2, 3]. The maximum Youden index (0.2) for the $\mathrm{N}$ Latex sFLC ratio enables determination of a ratio of 5.4 (specificity and sensitivity were $56.1 \%$ (95\% CI 46.5-65.4) and 62.9\% (95\% CI 49.774.8), respectively). Using this ratio, the positive predictive value (PPV) was $43.8 \%$ (95\% CI 33.3-54.7), and the negative predictive value (NPV) was 73.6\% (95\% CI 63.0-82.4). It can be noted that, as in previously described results, this ratio was lower than the SFLC ratio of 8 determined by Dispenzieri with the Freelite assay. 
A

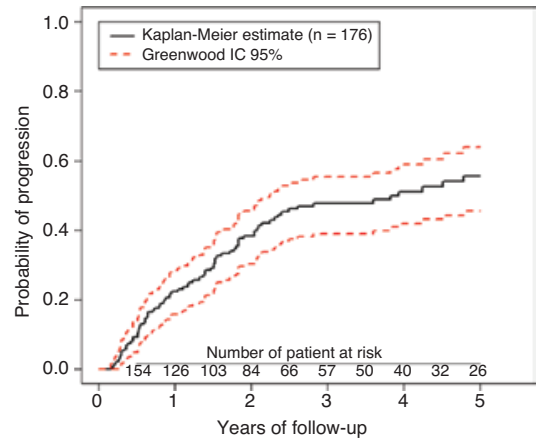

B

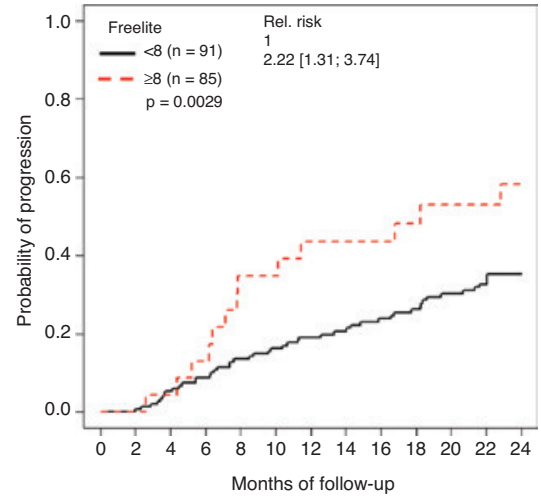

C
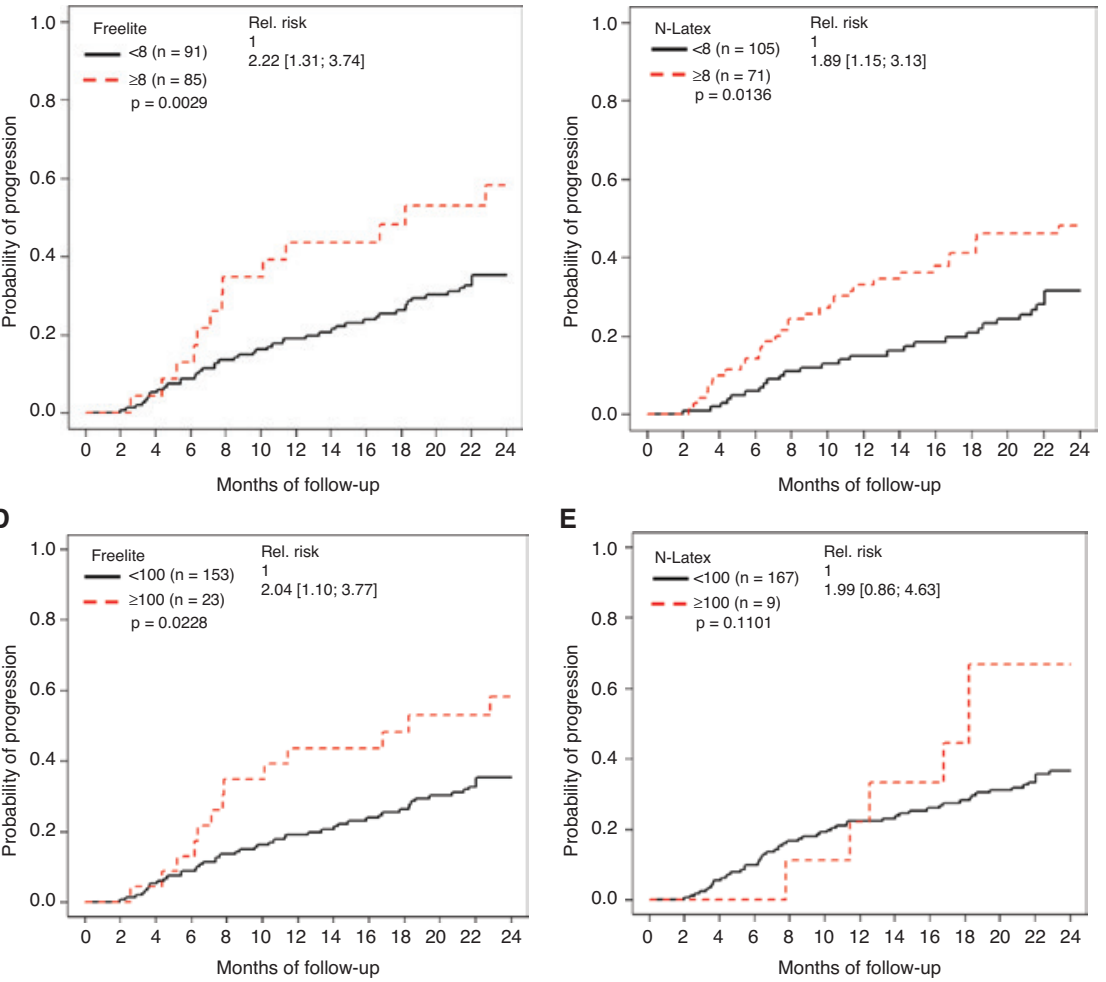

E

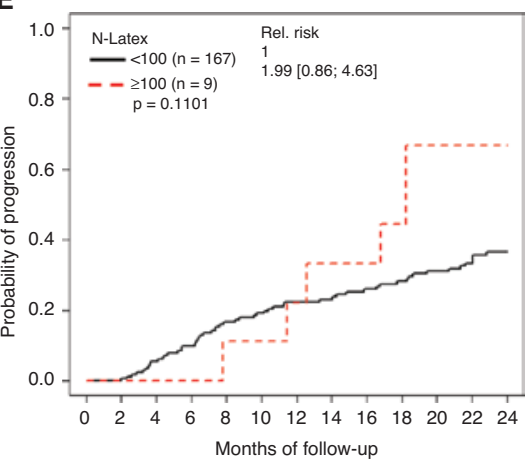

$\mathbf{F}$

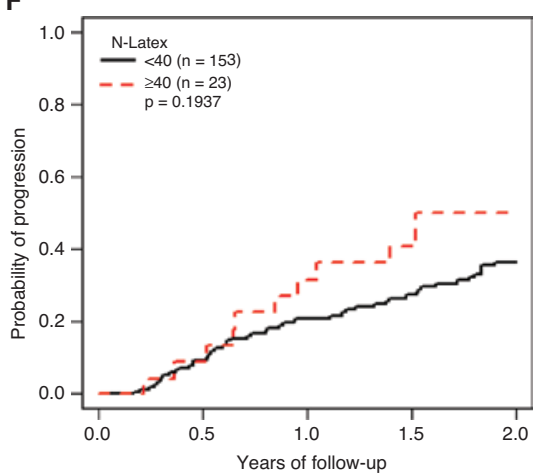

G

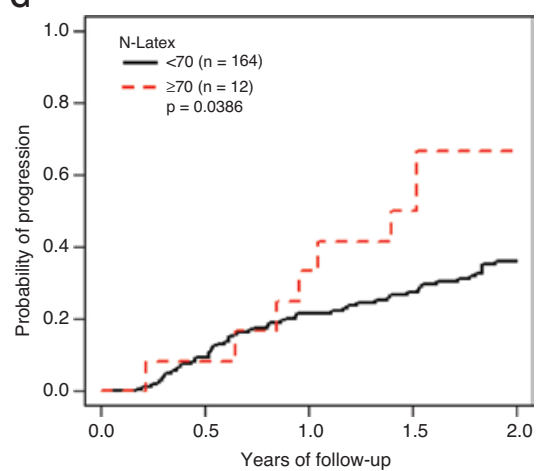

Figure 1: Progression to symptomatic myeloma stratified on SFLC ratio according to the $\mathrm{SFLC}$ assays used to measure $\mathrm{SFLC}$ and according to the different cut-offs used to identify high-risk and ultra-high risk SMM patients 2 years after diagnosis.

(A) Whole cohort $n=176$, (B) Freelite $s F L C$ ratio $\geq 8$, (C) $N$ Latex $s F L C$ ratio $\geq 8$, (D) Freelite $s F L C$ ratio $\geq 100$, (E) $N$ Latex $s F L C$ ratio $\geq 100$, (F) $N$ Latex sFLC ratio $\geq 40$, (G) N Latex sFLC ratio $\geq 70$.

An sFLC ratio over 8 was found for 85 patients with the Freelite assay (48.3\%), in a similar proportion to that reported in the study by Dispenzieri et al., which defined this ratio [2] (Figure 1B). Among these 85 patients, 39 had progressed to MM at 2 years, with an RR of 2.22 (95\% CI 1.31 ; 3.74 $)(\mathrm{p}=0.0029)$. 
A

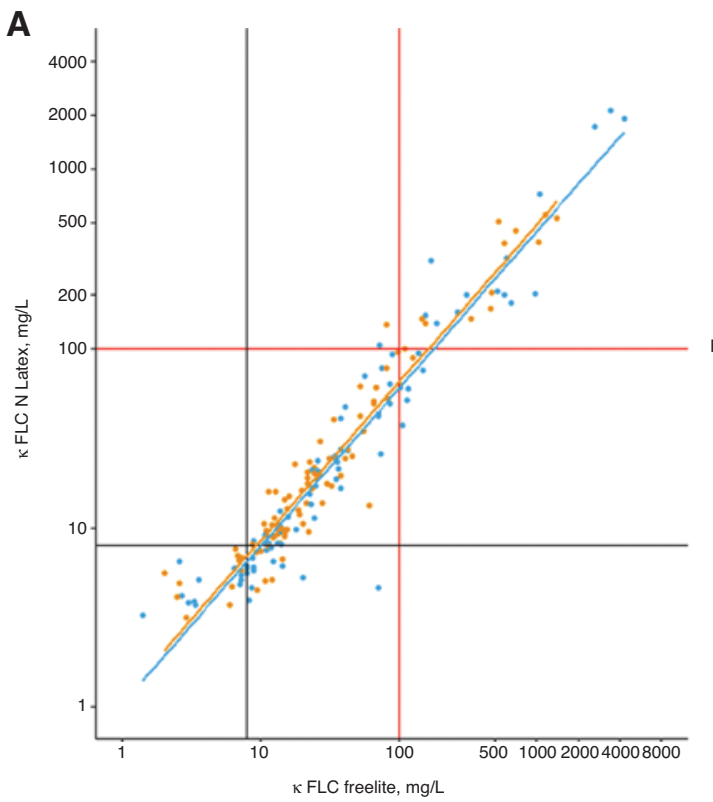

Correlation coefficients

No for progression to multiple myeloma coefficient $=0.9792[0.9699 ; 0.9856], \mathrm{p}<0.0001$ Yes for progression to multiple myeloma coefficient $=0.9821$ [0.9704; 0.9892$], \mathrm{p}<0.0001$

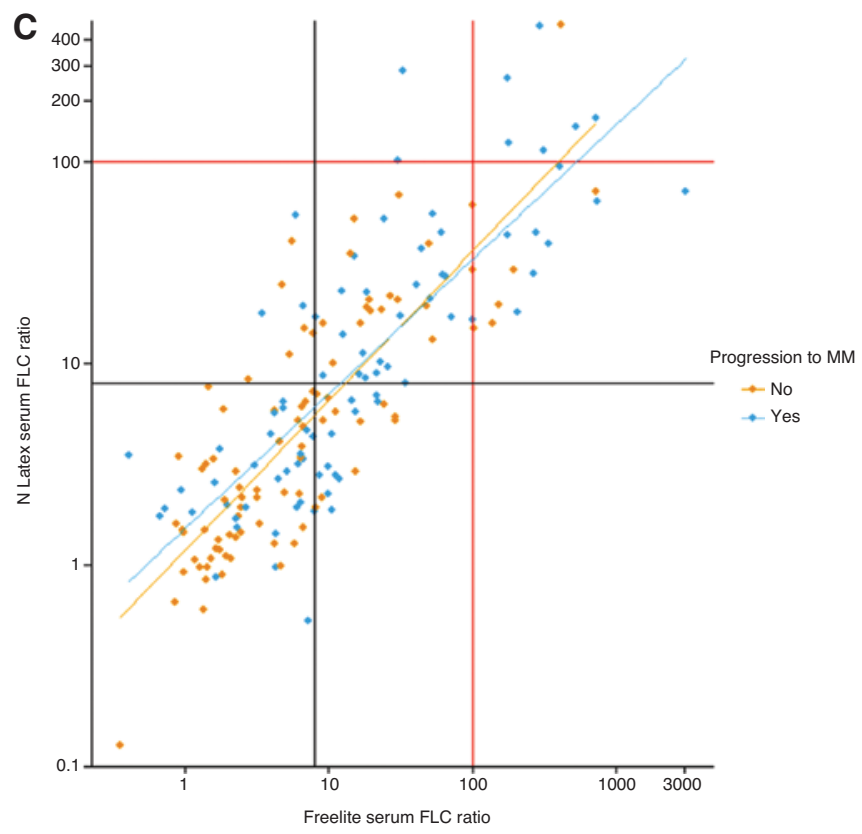

B

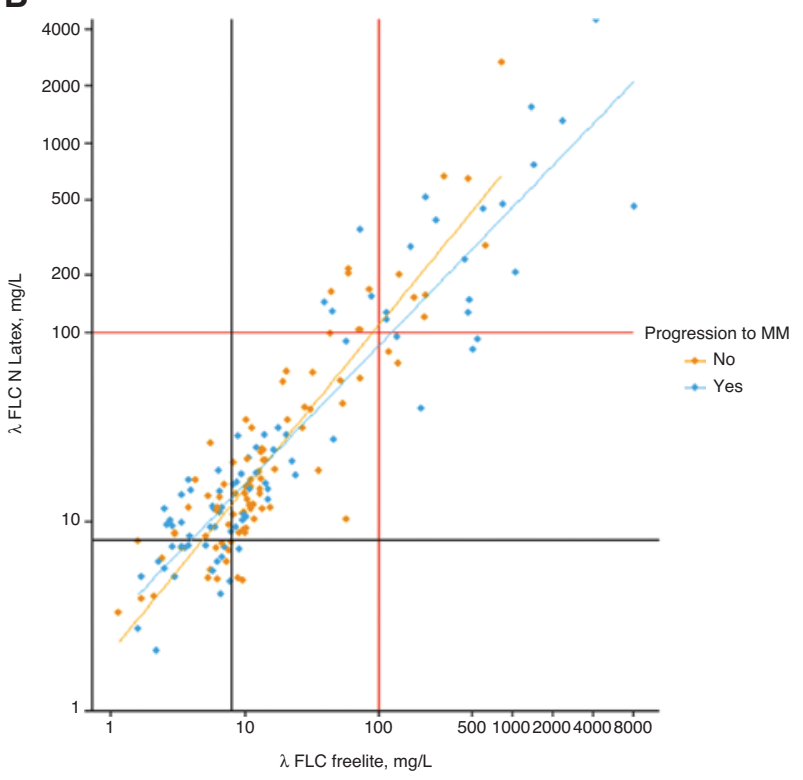

Correlation coefficients

No for progression to multiple myeloma coefficient $=0.7449[0.9500 ; 0.8169], p<0.0001$ No for progression to multiple myeloma coefficient $=0.7449[0.9500 ; 0.8169], \mathrm{p}<0.0001$
Yes for progression to multiple myeloma coefficient $=0.5676[0.3703 ; 0.7159], \mathrm{p}<0.0001$

Correlation coefficients

No for progression to multiple myeloma coefficient $=0.6277[0.5017 ; 0.7276], p<0.0001$

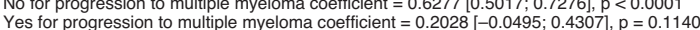

Figure 2: Correlation analysis of (A) $\kappa \mathrm{sFLC},(\mathrm{B}) \lambda \mathrm{sFLC}$ and (C) involved/non-involved sFLC ratio determined by Freelite and $\mathrm{N}$ Latex sFLC assays $(n=176)$.

Blue dots: patients with progression to symptomatic MM within 2 years. Yellow dots: patients without disease progression within 2 years.

With the N Latex assay; 71 (40.3\%) patients had an sFLC ratio $\geq 8$ (Figure 1C), and among them 32 progressed to MM, with an RR of $1.89(95 \%$ CI 1.15; 3.13) $(\mathrm{p}=0.0129)$.

According to these results, the $\mathrm{N}$ Latex assay with an sFLC ratio higher than 8 appears relevant to identify a subgroup of SMM patients with a high risk of progression to MM (Figure $1 \mathrm{~B}-\mathrm{C}$ ).
We then studied agreement in classifying high-risk patients ( $\mathrm{FFLC}$ ratio $\geq 8$ ). These results are presented in Table 2A. In our study, $50 \%$ of the patients with an sFLC ratio $\geq 8$ with the two tests had indeed progressed from SMM to MM at 2 years. In contrast, $26.8 \%$ of patients with sFLC ratios $<8$ with Freelite and $\mathrm{N}$ Latex had progressed to MM at 2 years. There were a few discordant results (18\% 
Table 2: Agreement in classifying patients according to SFLC ratio on $\mathrm{N}$ Latex and Freelite for a ratio of 8 (A), a ratio of 100 (B) and a ratio of $70(\mathrm{C})$

\begin{tabular}{lrrr}
\hline A. & \multicolumn{2}{c}{ N Latex SFLC ratio } & Total \\
\cline { 2 - 3 } & \multicolumn{2}{c}{$<$} & \\
\hline Freelite sFLC ratio & & $<8$ & \\
$\geq 8$ & $62(30)^{\mathrm{a}}$ & $23(8)^{\mathrm{a}}$ & 85 \\
$<8$ & $9(2)^{\mathrm{a}}$ & $82(22)^{\mathrm{a}}$ & 91 \\
Total & 71 & 105 & 176 \\
\hline
\end{tabular}

$\kappa$ coefficient $=0.6340[0.5208 ; 0.7471] p<0.0001 . \%$ agreement $81.8 \%$.

\begin{tabular}{lrrr}
\hline B. & \multicolumn{2}{c}{ N Latex sFLC ratio } & Total \\
\cline { 2 - 3 } & $\mathbf{2 1 0 0}$ & $<100$ & \\
\hline Freelite sFLC ratio & & \\
$\geq 100$ & $7(4)^{\mathrm{a}}$ & $16(8)^{\mathrm{a}}$ & 23 \\
$<100$ & $2(2)^{\mathrm{a}}$ & $151(48)^{\mathrm{a}}$ & 153 \\
Total & 9 & 167 & 176 \\
\hline
\end{tabular}

$\kappa$ coefficient $=0.3929[0.1754 ; 0.6103] \mathrm{p}<0.0001 . \%$ agreement $89.7 \%$.

\begin{tabular}{rrr}
\hline C. & N Latex sFLC ratio & Total \\
\cline { 2 - 3 } & 270 & $<70$
\end{tabular}

\begin{tabular}{lrrr}
\hline Freelite SFLC ratio & & & \\
$\geq 100$ & $10(6)^{\mathrm{a}}$ & $13(6)^{\mathrm{a}}$ & 23 \\
$<100$ & $2(2)^{\mathrm{a}}$ & $151(48)^{\mathrm{a}}$ & 153 \\
Total & 12 & 164 & 176 \\
\hline
\end{tabular}

$\kappa$ coefficient $=0.5292[0.3243 ; 0.7342] \mathrm{p}<0.0001 . \%$ agreement $91.5 \%$. ${ }^{a}(n)$, number of patients who progressed from SMM to MM at 2 years.

for an sFLC ratio of 8). Patients with discordant results for an SFCL ratio $\geq 8$ appeared to have a lower risk of progression than patients with an $\mathrm{sFLC}$ ratio $<8$ with both assays. However, these differences were not significant, probably due to the small numbers of patients in the subgroups.

\section{Evaluation of an sFLC ratio of 100}

In our study 23 patients presented a Freelite sFLC ratio $\geq 100$, while the $N$ Latex sFLC ratio was $\geq 100$ for nine patients; all patients with an SFLC ratio $\geq 100$ also had a concentration of the involved light chain $>100 \mathrm{mg} / \mathrm{L}$ with the corresponding assay. Twelve of these 23 patients with a Freelite sFLC ratio $\geq 100$ had progressed to symptomatic $\mathrm{MM}$ at 2 years (Figure 1D and Table 2B), resulting in a PPV of $56.5 \%$, while specificity was $91.2 \%$ (84.5; 95.7) (104/114), with a sensitivity of $21.0 \%$ (11.7; 33.2) (13/62). Applying the same cut-off of 100 to the N Latex sFLC ratio, PPV was
$66.7 \%$ (34.9; 90.1) (6/9), specificity 97.4\% (11/114), and sensitivity 9.7\% (6/62). The progression rate at 2 years for patients with a Freelite sFLC ratio $\geq 100$ was $57 \%$, and the resulting RR ratio was 2.04 (95\% CI 1.10; 3.77) $(p=0.0228)$. For the N Latex SFLC ratio $\geq 100$, the progression rate was $67 \%$ and the resulting $\mathrm{RR}$ ratio was 1.99 (95\% CI 0.86; 4.63) $(\mathrm{p}=0.1101)$ (Figure 1D and E).

The results of the agreement on classifying high-risk patients and ultra-high risk patients (sFLC ratio $\geq 100$ ) with the two assays are presented in Table 2B. In our study, $57.2 \%$ of patients with an sFLC ratio $\geq 100$ with the two tests had indeed progressed from SMM to MM at 2 years. There were a few discordant results $(10 \%$ for an sFLC ratio of 100). However, $31.1 \%$ of patients with sFLC ratios $<100$ with Freelite and N Latex had progressed to MM at 2 years. Patients with discordant results for an $\mathrm{SFCL}$ ratio $\geq 100$ seemed to have a similar risk of progression to patients with an sFLC ratio $\geq 100$ on both tests.

Thus, Freelite and N Latex sFLC ratios $\geq 100$ were both significantly associated with progression to symptomatic disease.

As previously suggested, and because of the generally lower sFLC values, the optimal N Latex SFLC ratio for identifying ultra-high-risk SMM patients could be lower than 100.

\section{SFLC ratio and renal failure}

In our cohort of 176 SMM patients, 15 patients presented an estimated glomerular filtration rate (eGFR) calculated with CKD-EPI that was lower than $60 \mathrm{~mL} / \mathrm{min}$ ( $\min 25 \mathrm{~mL} / \mathrm{min}$ ). Among them, four patients had a Freelite sFLC ratio $>100$ and three of them progressed to MM. Among these four patients, two patients had an N latex sFLC ratio $>100$ and progressed to MM.

Four patients with renal failure had a Freelite sFLC ratio between 8 and 100, and two of them progressed to MM. Among these four patients, only one patient had an $\mathrm{N}$ latex sFLC ratio $>8$ and progressed to MM.

On the other hand, only two patients with renal failure had an N latex sFLC ratio $>100$, and both progressed to MM. In the same way, four patients had an N Latex sFLC ratio between 8 and 100, and one of them progressed to $\mathrm{MM}$

In the whole population, the percentage of agreement for classifying patients according to the SFLC ratio on $\mathrm{N}$ Latex and Freelite for a ratio of 100 is $90 \%$ vs. $87 \%$ for classifying patients with eGFR $<60 \mathrm{~mL} / \mathrm{min}$ according to sFLC ratio on $\mathrm{N}$ Latex and Freelite for a ratio of 8. 
These results are presented in the Supplementary data.

\section{Evaluation of $\mathbf{N}$ Latex performances: SFLC ratio calculation}

To evaluate the ability of $\mathrm{N}$ latex to identify SMM patients who could potentially evolve to MM, we proposed to determine different sFLC ratios. Sensitivity, specificity, PPV and NPV for sFLC ratios of 10, 20, 40, 70, 90 and 120 were determined. The different performances of the test are summarized in Table 3 below. It can be noted that the ratios of 40 and 70 provided interesting findings: an N Latex sFLC ratio of 40 was found to have very similar performances to the Freelite sFLC ratio of 100 in our cohort with a specificity of $89.5 \%$ (82.3; 94.4) (vs. 91.2\% [84.5; 95.7]) and a sensitivity of $17.7 \%$ (9.2; 29.5) (vs. 21\% [11.7; 33.2]) (Table 3 and Figure 1F). An N Latex sFLC ratio of 70 appears interesting (Table 3 and Figure 1G) with adequate specificity of 96.5\% (91.3; 99.0) at the expense of sensitivity at $12.9 \%$ (5.7; 23.9). It can be noted that an N Latex sFLC ratio of 70 identified 12 patients; among them, eight had progressed to MM at 2 years, with an RR ratio of 2.22 (95\% CI 1.06; 4.68) $(\mathrm{p}=0.0357)$, resulting in a PPV of $66.7 \%(34.9 ; 90.1)$ with $96.5 \%$ (91.3; 99.0) specificity and $12.9 \%$ (5.7; 23.9) sensitivity. In addition, 10 patients had an $\mathrm{N}$ latex sFLC ratio $\geq 70$ and a Freelite sFLC ratio $\geq 100$, and among them, six patients had progressed from SMM to MM at 2 years, and the two patients with an N Latex sFLC ratio $\geq 70$ and a
Freelite sFLC ratio $<100$ had also progressed from SMM to $\mathrm{MM}$ at 2 years (Table $2 \mathrm{C}$ ).

Our results show that different cut-offs obtained with different assays enabled identification of ultra-high-risk SMM patients, but did not identify the same patients, and no cut-off identified all patients who were to progress from SMM to MM at 2 years.

\section{Discussion}

The interest of the sFLC ratio as a marker for progression of SMM to MM has been previously described and has radically changed patient monitoring, despite the different predictive value for progression in SMM $[25,26]$. sFLC ratios of 8 and 100 are associated with risk of progression to MM $[2,4]$, but the predictive value of an sFLC ratio $\geq 100$ for risk stratification is still debated [27, 28]. More recently, Lakshman et al. proposed to redefine the cut-offs for markers at diagnosis for the risk stratification of SMM. They concluded, on the basis of a sample of 421 SMM patients, that BMPC $>20 \%$, monoclonal protein $>20 \mathrm{~g} / \mathrm{L}$ and sFLC ratio >20 were significantly associated with a shorter time to progression and could be used to stratify patients with SMM [5]. All three studies were retrospective and used the Freelite assay.

Here, we report the evolution of a multicenter cohort of 176 French SMM patients, with clinical follow-up for a median of 56 months. We investigated the impact of the sFLC ratio on disease progression to MM using two

Table 3: Performance of the N Latex assay in predicting the evolution of SMM patients with different values for the SFLC ratio.

\begin{tabular}{|c|c|c|c|c|c|c|c|}
\hline & \multirow[t]{2}{*}{$\geq 8$} & \multirow[b]{2}{*}{$\geq 10$} & \multirow[b]{2}{*}{$\geq 20$} & \multirow[b]{2}{*}{$\geq 40$} & \multirow[b]{2}{*}{$\geq 70$} & \multicolumn{2}{|c|}{ N Latex sFLC ratio } \\
\hline & & & & & & $\geq 90$ & $\geq 120$ \\
\hline \multicolumn{8}{|l|}{ Patients, $\mathrm{n}$} \\
\hline True positives & 32 & 27 & 19 & 11 & 8 & 7 & 5 \\
\hline False positives & 39 & 37 & 22 & 12 & 4 & 3 & 2 \\
\hline True negatives & 75 & 77 & 92 & 102 & 110 & 111 & 112 \\
\hline False negatives & 30 & 35 & 43 & 51 & 54 & 55 & 57 \\
\hline \multicolumn{8}{|l|}{ Performances } \\
\hline \multirow[t]{2}{*}{ Sensitivity } & $51.6 \%$ & $43.5 \%$ & $30.6 \%$ & $17.7 \%$ & $12.9 \%$ & $11.3 \%$ & $8.1 \%$ \\
\hline & {$[38.6 ; 64.5]$} & {$[31.0 ; 56.7]$} & {$[19.6 ; 43.7]$} & {$[9.2 ; 29.5]$} & {$[5.7 ; 23.9]$} & {$[4.7 ; 21.9]$} & {$[2.7 ; 17.8]$} \\
\hline \multirow[t]{2}{*}{ Specificity } & $65.8 \%$ & $67.5 \%$ & $80.7 \%$ & $89.5 \%$ & $96.5 \%$ & $97.4 \%$ & $98.2 \%$ \\
\hline & {$[56.3 ; 74.4]$} & {$[58.1 ; 76.0]$} & {$[72.3 ; 87.5]$} & {$[82.3 ; 94.4]$} & {$[91.3 ; 99.0]$} & {$[92.5 ; 99.5]$} & {$[93.8 ; 99.8]$} \\
\hline \multirow[t]{2}{*}{ PPV } & $45.1 \%$ & $42.2 \%$ & $46.3 \%$ & $47.8 \%$ & $66.7 \%$ & $70.0 \%$ & $71.4 \%$ \\
\hline & {$[33.2 ; 57.3]$} & {$[29.9 ; 55.2]$} & {$[30.7 ; 62.6]$} & {$[26.8 ; 69.4]$} & {$[34.9 ; 90.1]$} & {$[34.8 ; 93.3]$} & {$[29.0 ; 96.3]$} \\
\hline \multirow[t]{2}{*}{ NPV } & $71.4 \%$ & $68.8 \%$ & $68.1 \%$ & $66.7 \%$ & $67.1 \%$ & $66.9 \%$ & $66.3 \%$ \\
\hline & {$[61.8 ; 79.8]$} & {$[59.3 ; 77.2]$} & {$[59.6 ; 75.9]$} & {$[58.6 ; 74 . \%]$} & {$[59.3 ; 74.2]$} & {$[59.2 ; 74.0]$} & {$[58.6 ; 73.4]$} \\
\hline
\end{tabular}

PPV, positive predictive value; NPV, negative predictive value. 
different, commercially available methods for sFLC determination, Freelite and N Latex sFLC. For N Latex sFLC, this is the first study to investigate the use of this assay for risk prediction in SMM.

We observed an acceptable correlation between the two sFLC ratio methods, as previously reported [14, 17], although a few differences in absolute values prohibit the interchangeable use of the two different assay systems. Results presented in Bland-Altman difference plots highlighted that, as previously described, the two assays yielded similar results when values are in normal ranges but diverged substantially for high values (Supplementary Figure).

Both Freelite and N Latex SFLC ratios $\geq 8$ were predictive of disease progression ( $p=0.0029$ and 0.0136 , respectively) and identified high-risk SMM. In our study, an N Latex sFLC ratio $\geq 100$ was associated with an increased risk of disease progression. Because of the small number of patients with an sFLC ratio $\geq 100$, the significance level was not reached $(\mathrm{p}=0.1101, \mathrm{n}=9)$.

To justify the treatment of ultra-high-risk SMM, the IMWG recommendations allowed the identification of patients with an $80 \%$ risk of progression within 2 years, at $95 \%$ specificity [18]. While the initial study by Larsen et al. [4] indicated a performance very close to these criteria, with a PPV of $70 \%$ and a specificity of $97 \%$, subsequent studies could not reach the targets set, especially for the PPV target of $80 \%$ [4, 27, 28]. Sørrig's study published in 2016 failed to confirm the association described by Larsen et al., with a 57\% PPV for a Freelite sFLC ratio $\geq 100$, and $67 \%$ PPV for an N Latex sFLC ratio $\geq 100$ [28]. In our cohort, compared to a Freelite sFLC ratio of 100, an $\mathrm{N}$ Latex sFLC ratio of 70 provided a similar performance, with a slightly better PPV.

As confirmed by Wu et al., an sFLC ratio $\geq 100$ using the Freelite assay is a marker for high risk of progression [24].

Regarding patients with renal impairment, only 15 patients presented an eGFR $<60 \mathrm{~mL} / \mathrm{min}$. However, the correlation between the two assays is similar to that for the whole cohort, and the cut-off ratios predicted progression to MM in a similar manner.

According to our results, we can conclude that the Freelite sFLC and N Latex sFLC ratios are prognostic markers for disease progression among SMM patients. Compared to Freelite sFLC ratios $\geq 8$ and $\geq 100$, the N Latex sFLC ratios provided a similar performance and provided an efficient identification of high-risk and ultra-high risk SMM patients, suggesting that the N Latex assay could be used for SMM patient monitoring. Physicians following the IMWG guidelines now treat ultra-high risk SMM patients to prevent organ damage or symptoms, calling on the vast range of available treatments and more effective regimens.
However, treating these asymptomatic patients exposes them to complications, and the timing of treatment for SMM is still controversial [29-31]. Thus, physicians need to ensure their patients will draw individual benefit, and they must be confident that they can use a published cut-off, without risking over- or under-treatment. In this context, we aimed to determine other ratios for the $\mathrm{N}$ Latex assay. We can thus suggest that an N Latex SFLC ratio of 70 provides similar performances to a Freelite sFLC ratio of 100, with slightly better PPV. If physicians apply the cut-off sFLC ratios of 8 and 100 (Freelite sFLC assay), they will safely identify high-risk and ultra-high risk SMM patients.

Acknowledgments: The authors thank Siemens Healthcare Diagnosis for technical support and providing reagents, in particular, Carola Wagner and Claire Bouvet.

Author contributions: All the authors have accepted responsibility for the entire content of this submitted manuscript and approved submission.

Research funding: None declared.

Employment or leadership: None declared.

Honorarium: None declared.

Competing interests: The funding organization(s) played no role in the study design; in the collection, analysis, and interpretation of data; in the writing of the report; or in the decision to submit the report for publication.

\section{References}

1. International Myeloma Working Group. Criteria for the classification of monoclonal gammopathies, multiple myeloma, and related disorders: a report of the International Myeloma Working Group. Br J Haematol 2003;121:749-57.

2. Dispenzieri A, Kyle RA, Katzmann JA, Therneau TM, Larson D, Benson J, et al. Immunoglobulin free light chain ratio is an independent risk factor for progression of smoldering (asymptomatic) multiple myeloma. Blood 2008;111:785-9.

3. Dispenzieri A, Kyle R, Merlini G, Miguel JS, Ludwig H, Hajek $\mathrm{R}$, et al. International Myeloma Working Group guidelines for serum-free light chain analysis in multiple myeloma and related disorders. Leukemia 2009;23:215-24.

4. Larsen JT, Kumar SK, Dispenzieri A, Kyle RA, Katzmann JA, Rajkumar SV. Serum free light chain ratio as a biomarker for high-risk smoldering multiple myeloma. Leukemia 2013;27:941-6.

5. Lakshman A, Rajkumar SV, Buadi FK, Binder M, Gertz MA, Lacy $M Q$, et al. Risk stratification of smoldering multiple myeloma incorporating revised IMWG diagnostic criteria. Blood Cancer J 2018;8:59.

6. López-Corral L, Gutiérrez NC, Vidriales MB, Mateos MV, Rasillo A, García-Sanz R, et al. The progression from MGUS to smoldering myeloma and eventually to multiple myeloma involves a clonal expansion of genetically abnormal plasma cells. Clin Cancer Res Off J Am Assoc Cancer Res 2011;17:1692-700. 
7. Kyle RA, Remstein ED, Therneau TM, Dispenzieri A, Kurtin PJ, Hodnefield JM, et al. Clinical course and prognosis of smoldering (asymptomatic) multiple myeloma. N Engl J Med 2007;356:2582-90.

8. Cesana C, Klersy C, Barbarano L, Nosari AM, Crugnola M, Pungolino E, et al. Prognostic factors for malignant transformation in monoclonal gammopathy of undetermined significance and smoldering multiple myeloma. J Clin Oncol Off J Am Soc Clin Oncol 2002;20:1625-34.

9. Ravi P, Kumar S, Larsen JT, Gonsalves W, Buadi F, Lacy MQ, et al. Evolving changes in disease biomarkers and risk of early progression in smoldering multiple myeloma. Blood Cancer J 2016;6:e454.

10. Fernández de Larrea C, Isola I, Pereira A, Cibeira MT, Magnano L, Tovar N, et al. Evolving M-protein pattern in patients with smoldering multiple myeloma: impact on early progression. Leukemia 2018;32:1427-34.

11. Rajkumar SV, Dimopoulos MA, Palumbo A, Blade J, Merlini G, Mateos M-V, et al. International Myeloma Working Group updated criteria for the diagnosis of multiple myeloma. Lancet Oncol 2014;15:e538-48.

12. Wu V, Moshier E, Leng S, Barlogie B, Cho HJ, Jagannath S, et al. Risk stratification of smoldering multiple myeloma: predictive value of free light chains and group-based trajectory modeling. Blood Adv 2018;2:1470-9.

13. Bradwell AR, Carr-Smith HD, Mead GP, Tang LX, Showell PJ, Drayson MT, et al. Highly sensitive, automated immunoassay for immunoglobulin free light chains in serum and urine. Clin Chem 2001;47:673-80.

14. te Velthuis H, Knop I, Stam P, van den Broek M, Bos HK, Hol S, et al. N Latex FLC - new monoclonal high-performance assays for the determination of free light chain kappa and lambda. Clin Chem Lab Med 2011;49:1323-32.

15. Campbell JP, Heaney JL, Shemar M, Baldwin D, Griffin AE, Oldridge $E$, et al. Development of a rapid and quantitative lateral flow assay for the simultaneous measurement of serum $\kappa$ and $\lambda$ immunoglobulin free light chains (FLC): inception of a new near-patient FLC screening tool. Clin Chem Lab Med 2017; 55:424-34.

16. Jacobs JF, de Kat Angelino CM, Brouwers HM, Croockewit SA, Joosten I, van der Molen RG. Evaluation of a new free light chain ELISA assay: bringing coherence with electrophoretic methods. Clin Chem Lab Med 2018;56:312-22.

17. Hoedemakers RM, Pruijt JF, Hol S, Teunissen E, Martens H, Stam $P$, et al. Clinical comparison of new monoclonal antibody-based nephelometric assays for free light chain kappa and lambda to polyclonal antibody-based assays and immunofixation electrophoresis. Clin Chem Lab Med 2012;50:489-95.

18. Di Noto G, Cimpoies E, Dossi A, Paolini L, Radeghieri A, Caimi L, et al. Polyclonal versus monoclonal immunoglobulin-free light chains quantification. Ann Clin Biochem 2015;52:327-36.
19. Hutchison CA, Cockwell P, Cook M. Diagnostic accuracy of monoclonal antibody based serum immunoglobulin free light chain immunoassays in myeloma cast nephropathy. BMC Clin Pathol 2012;12:12.

20. Carr-Smith HD, Jenner EL, Evans JA, Harding SJ. Analytical issues of serum free light chain assays and the relative performance of polyclonal and monoclonal based reagents. Clin Chem Lab Med 2016;54:997-1003.

21. Moreau C, Autier B, Cavey T, Rouger E, Norwood J, Bendavid C, et al. Evaluation of the impact of renal failure on correlation and concordance between 2 free light chain assays. Clin Lymphoma Myeloma Leuk 2016;16:693-704.

22. Sabatino R, Perrone A, Cuomo M, Liotti S, Barchiesi V, Cantile M, et al. Analytical criticalities associated to different immunological methods for serum free light chain detection in plasma cell dyscrasias: a description of particular clinical cases. Int J Mol Sci 2017;18:804.

23. Messiaen A-S, De Sloovere MM, Claus P-E, Vercammen M, Van Hoovels L, Heylen O, et al. Performance evaluation of serum free light chain analysis: nephelometry vs. turbidimetry, monoclonal vs. polyclonal reagents. Am J Clin Pathol 2017;147:611-22.

24. Rajkumar SV, Larson D, Kyle RA. Diagnosis of smoldering multiple myeloma. N Engl J Med 2011;365:474-5.

25. Atrash S, Robinson M, Slaughter D, Aneralla A, Brown T, Robinson J, et al. Evolving changes in M-protein and hemoglobin as predictors for progression of smoldering multiple myeloma. Blood Cancer J 2018;8:107.

26. Aljama MA, Sidiqi MH, Lakshman A, Dispenzieri A, Jevremovic D, Gertz MA, et al. Plasma cell proliferative index is an independent predictor of progression in smoldering multiple myeloma. Blood Adv 2018;2:3149-54.

27. Kastritis E, Terpos E, Moulopoulos L, Spyropoulou-Vlachou M, Kanellias N, Eleftherakis-Papaiakovou E, et al. Extensive bone marrow infiltration and abnormal free light chain ratio identifies patients with asymptomatic myeloma at high risk for progression to symptomatic disease. Leukemia 2013;27:947-53.

28. Sørrig R, Klausen TW, Salomo M, Vangsted AJ, $\varnothing$ stergaard B, Gregersen $\mathrm{H}$, et al. Smoldering multiple myeloma risk factors for progression: a Danish population-based cohort study. Eur J Haematol 2016;97:303-9.

29. Mateos M-V, González-Calle V. Smoldering Multiple Myeloma: Who and When to Treat. Clin Lymphoma Myeloma Leuk 2017; 17:716-22.

30. Kumar SK. Timing of treatment of smoldering myeloma: delay until progression. Blood Adv 2018;2:3050-3.

31. Mateos M-V, González-Calle V. Timing of treatment of smoldering myeloma: early treatment. Blood Adv 2018;2:3045-9.

Supplementary Material The online version of this article offers supplementary material (https://doi.org/10.1515/cclm-2018-1369). 